\title{
Navigating the Post-COVID-19 Era of 'Next Normal' in the Context of Philippine Higher Education
}

\author{
Michael B. Cahapay \\ ${ }^{1}$ College of Education, Mindanao State University, General Santos City, Philippines \\ Imbcahapay@up.edu.ph
}

\begin{abstract}
This year holds an important promise to humanity as codified treatments to control the effects of the COVID-19 are already in the final phase of the clinical test. With that positive note, there is also a new glimmer of hope in higher education as it will navigate another challenging but interesting era. This essay article explores the concept of a post-COVID-19 era called 'next normal' in the context of Philippine higher education. Drawing from the experiences, observations, and reflections, the researcher conceptually introduces the idea of a next normal and then discusses it in the context of Philippine higher education. This paper contends that the next normal is not the 'what' but the 'how' as higher education navigates beyond the COVID-19 crisis. It is characterized by an active reshaping process that involves the following actions: bolstering teaching and learning continuity, developing educational recovery plans, keeping the machine running as an obligation, and attuning the curriculum to the next demands. A conclusion answering the metaphorical cure to COVID-19 in higher education to pave the way to the next normal is presented. Finally, a next normal framework for higher education which authorities and teachers may consider in educational planning is offered at the end of the paper
\end{abstract}

Keywords: Next Normal, Higher Education, COVID-19 Crisis, Philippines

\section{Introduction: The next normal concept}

Within two decades, there have appeared at least three highly communicable human coronaviruses [1]. One of these coronaviruses is the COVID-19, a new strain of severe acute respiratory syndrome caused by a novel coronavirus [2]. Its origin was first reported in people exposed to a market in China and transmitted to humans through an unknown intermediary. It has rapidly spread across six continents and in more than a hundred countries [3] in a short period. Towards the end of this year on December 26, 2020, it was reported that there have been 78,604,532 confirmed positive cases of COVID-19, including 1,744,235 mortalities [4].

Since COVID-19 spread worldwide, it saw how the crisis has radically transformed the way people live, work, and interacts. Within the educational context, massive closures caused learners to have reduced time to study, change in interactions, indications of stress, decreased motivation, and forced remote learning [5]. On the other hand, teachers must adjust at pressured strides not only to new teaching approaches, methods, and strategies but also to their limitations, resulting in high levels of anxiety [6]. After a major learning disruption due to school closures, countries have gradually suspended the restrictions while preserving

Article history:

Received (October 16, 2020), Review Result (November 19, 2020), Accepted (December 22, 2020)

Print ISSN: 2207-5380, eISSN: 2207-290X AJEMR

Copyright (C) 2020 Global Vision Press (GV Press) 
important protective measures. Authorities are confronted by the problems of planning how education will be delivered in such uncertain periods. Not one exactly knows what the future holds for the education and higher education sector.

The promise of a codified vaccine for the COVID-19 is a light at the end of the tunnel of this extraordinary global crisis. As the race to coronavirus medicine is a little more than halfway through the finish line, but that does not mean the education and higher education sector will now leave how it is at present or the 'new normal' and return to how it was in the past or the 'old normal' any time soon. With fingers crossed, the emergency remote education will not go on for too much longer. But it is also clear that some things will have changed. Some scholars in the educational field [7] are already thinking about the phenomenon dubbed as the next normal and how it looks from the educational perspective.

The concept of the next normal was coined by Sneader \& Singhal [8]. It is different from the old normal and the relatively

more immediate concept of the new normal. According to an article [9], the concept of 'new' denotes stability but 'next' always looks forward. It explained that new describes something current, and it may quickly become old. For example, a teaching method may be new within 500 miles and today, but it may be old beyond and tomorrow. The concept of next is a more complex one, indicating a continuous motion. It means the phenomenon after the current phenomenon. Applied to our situation now, it is normal after the current normal caused by the COVID-19 crisis. It can also be elaborated that "normal" in a general sense is a relative word, thus the next normal is contextual from person to person, sector to sector, and country to country [7].

Within the Philippine higher education context, the new normal had original instructional plans rendered aside. There was a quick obligatory transfer to forms of emergency remote education [10][11][12]. The teachers and students suffered from varying levels of anxiety, fear, stress, and depression [13][14][15]due to the quick adaptations required in the changed situations. The multidimensional changes have revealed glaring digital divides and stark educational gaps [16][17][18]. Despite how bleak the condition looks and how ominous the time feels, however, there remains optimism. The higher education sector is traversing the current global crisis and the responses it takes will define how it will step into the next era. While it makes both ends meet to continue education amid the difficult situation, it also needs to position itself to take off after the crisis has passed towards stepping into the dawning of a post-COVID-19 era of the next normal.

Thus, this article aims to explore the next normal in Philippine higher education. Considering this aim, it is important to draw perspectives from the experiences, observations, and reflections of the current situation to be able to configure the future of higher education in this situation where no one holds a tested solution to the continuing quandary. Having introduced the concept of a next normal, this paper will discuss how higher education will get into such a post-COVID-19 era. Finally, based on the discussion, it will provide a framework that authorities and teachers may consider in planning the next normal in higher education.

\section{The next normal in Philippine higher education}

Emerging conversations in different spheres including education led thinkers to the concept of the next normal but nobody has a perspective of what it exactly looks like. We certainly can contend that higher education will not return to its old self. However, pondering on 'what' will we get there might not be the issue, but 'how' we would get there might be. 
Thus, amid the sea of uncertainties, the next normal in Philippine higher education will be more of a constant process that involves the following enabling actions.

\subsection{Bolster teaching and learning continuity}

The Commission on Higher Education [19] urged Philippine colleges and universities earlier to develop their educational continuity plans which articulate the flexible learning approaches anchored on the extant resources of the institution, teachers, and students. As the ferocity of COVID-19 is expected even in the next normal, however, higher education institutions should bolster their continuity plans for teaching and learning. The key to bolstering teaching and learning continuity in the next normal is to build resilience in the context of higher education institutions.

Resilience in the context of higher education institutions is to be able to take the negative impacts of the next normal but still operate to survive the challenges. It is advised that to manage continuity of teaching and learning in the next normal, higher education institutions should focus on crisis management and instructional delivery. This involves the constant examination of the measures applied [20]. Borrowing further from the business ideas [21], it should be known that resilient higher education institutions do not only have strong educational continuity plans in place but also perform timely enactment to support their essential functions.

Similarly, the UNICEF [22] focused on discussing resilient education in terms of instructional delivery. It added that a resilient education is not just about supplementary instructional delivery. It is about safeguarding that all initiatives at all levels meet to help the transformation of schools with attention on two crucial aspects: transforming pedagogy by developing more inclusive and adaptable curriculum and instructional practices that address the individual needs of every learner, and transforming school culture and structure so that inclusion, respect, and support are at the center of the philosophy and actions of the schools.

\subsection{Develop educational recovery plans}

As Philippine higher education will survive from its current educational condition to the next normal, the development of an educational recovery plan would be another facilitating practice in the process [21]. At some points after the new normal, higher education leaders will be faced with new pressures from different directions. The teachers, students, parents, and other stakeholders will look for a sense of clarity and assurance with the advent of the next normal. Thus, higher education institutions should review their previous educational continuity plans and draw lessons from their experiences to develop their educational recovery plans [20]. The educational continuity plan should be complemented with an annex or standalone plan that details the ways to recover from the situation.

According to the Texas School Safety Center [23], recovery is a procedure to offer guidance for how to manage short-, medium-, and long-term recuperation efforts after major emergencies such as the present COVID-19 crisis. Furthermore, recovery plans may be an annex or standalone plan to educational continuity plan which is used amid the emergency periods. It should articulate the ways to overcome the crisis and propose actions to implement after the crisis to return to normalcy. Such recovery annex and standalone plan should consider four important aspects of recovery for higher education environments. These aspects include the academic, physical, fiscal, and psychological, and emotional.

The Readiness and Emergency Management for Schools [24] discussed these four aspects which can be applied in the formulation of recovery plans for the COVID-19 crisis. The 
higher education institutions should ponder on the following considerations when developing their courses of action in the recovery process:

- Academic recovery: when the school should be closed and reopened, and who has the authority to do so; what temporary spaces the school may use if school buildings cannot be immediately reopened; how to provide alternative educational programming if students cannot physically restart.

- Physical recovery: how to document school assets, including physically accessible facilities, in case of damage; who has expert knowledge of the assets of the school, and how and where they will access records to verify current assets after disaster strikes; how the school will work with utility and insurance companies before an emergency to support a quicker recovery.

- Fiscal recovery: how leadership will be included; how staff will receive timely and factual information regarding returning to work; what sources the school may access for emergency relief funding.

- Psychological and emotional recovery: who will serve as the team leader; where counselling and psychological first aid will be provided; how teachers will create a calm and supportive environment for the students, share basic information about the incident, provide psychological first aid, and identify students and staff who may need immediate crisis counselling; who will provide trained counsellors; how to address the counselling needs.

It should be noted that no best suggestion fits all higher education institutions in these considerations. Each higher education institution should make an answer to these considerations based on their contexts. For example, in academic recovery, the provision of alternative educational programming if students cannot physically restart would largely depend on the context of the higher education institution and its students. Some higher education institutions and students with access to high technology may continue much of the instruction through online learning. Other higher education institutions and students located in rural areas of the country may consider other remote modalities like print modular learning. As pointed out, no best suggestion exists for each consideration in the recovery plan. It is important to contextualize them in every higher education institution and its situation.

\subsection{Keep the machine running as an obligation}

There are demands and indications of the return to face-to-face classes in Philippine colleges and universities following carefully developed safety protocols and contingency measures [25]. Emerging from the secure spaces of home, it is expected that the next normal in higher education will be a hybrid of remote and face-to-face instruction. However, to keep going with the safety protocols, it should be an obligation of higher education institutions to use technology as an instructional implementation tool more than ever. Contextualizing the points raised earlier [20] and pondering this task as an obligation rather than a choice, there is a need for higher education institutions to consider the following suggestions:

- Customize instructional delivery models that suit the resources of the students. These models may range from complete digital to blended learning. Higher education institutions should engage students in this action to assess the learner needs and demonstrate how to support students amid the challenges.

- Since higher education instruction is based on discipline curriculum design, the actual application of specialized knowledge is an essential element of the learning process. Thus, the 
actual learning opportunities for laboratories, demonstrations, residences, and internships should be carefully arranged face-to-face in combination with online modalities, strictly following safety precautionary rules and measures.

- Aside from the access to teaching and learning, there should be new approaches to usher students and assist them to maximally access support services. There should be more access to organizations and clubs, guidance and counselling, information and communication, and other student support services that are essential to their overall development.

- Where digital disparities exist, higher education institutions should consider means to help students and prevent inequalities. For example, laptop loan programs, phone donation drives, or partnerships with concerned agencies to enable technology access can be forged by the higher education institutions for the students.

\subsection{Attune the curriculum to the next demands}

The demand for technological skills as a result of new practices, for example, will be one of the next demands. As the industries, including malls, schools, clinics, and other institutions, will usher themselves into the next normal and continue observing safety precautionary rules and measures, technology skills will continue to become essential skills in the work more than ever. With technological skills, also come the set of skills called "soft skills." The crisis has challenged human resilience. As the industries brace for the next normal, it is soft skills like adaptability, innovation, flexibility, commitment, creativity, leadership, and ingenuity that will rise in demand of the next generation of workers [26][27][28].

The same trend in the Philippine industries can be observed. A job recruitment portal official advised that job applicants must advance their digital skills to be hired [29] in the next normal. There are even emerging careers or new jobs such as digital marketers and other technical support jobs. The teacher education curriculum may have to reconsider emphasis on the development of technology, pedagogy, and content knowledge or TPACK [30] to its students who will be teachers in the next normal age. These next demands in the form of skills serve as useful inputs on what essential outcomes the Philippine higher education institutions should develop for their students. Thus, they should consider redesigning the curriculum of their existing programs or new programs, if it should remain relevant, appropriate, and responsive in the next normal.

Lastly, considering these next demands to which the curriculum must be aligned, there is a need to reshape education from the lens of the elements of the curriculum [31]. The rise of the next demands will necessitate the reconsideration of the goals, contents, approaches, and evaluations in redeveloping the curriculum. For instance, the focus on the development of technological skills to the college students will need the reframing of the goals of the curriculum and the list of contents will have to be updated. There will also be an increasing move to independent learning, thus teaching approaches and evaluation will have to be attuned. The higher education institutions should carefully examine the next demands and revisit these elements in the curriculum.

\section{Conclusion: The next normal framework}

The cure to COVID-19 to pave the way to the next normal in Philippine higher education is not only any codified medicine. Effective treatment will be obtainable soon so that higher education and other sectors will get back to their feet. This paper contends, however, that a 
key to survival to the next normal also lies in how colleges and universities take on the next challenges. The next normal is not a destination, but a process that consists of a series of contextualized actions. This paper concludes that higher education institutions need to bolster teaching and learning continuity, develop educational recovery plans, keep the machine running as an obligation, and attune the curriculum to the next demands.

Based on these ideas, this paper recommends a framework that will guide higher education institutions as they navigate the next normal. This framework is a product of the constant reflections of the researcher in the field and in the process of developing this paper. It is shown below.

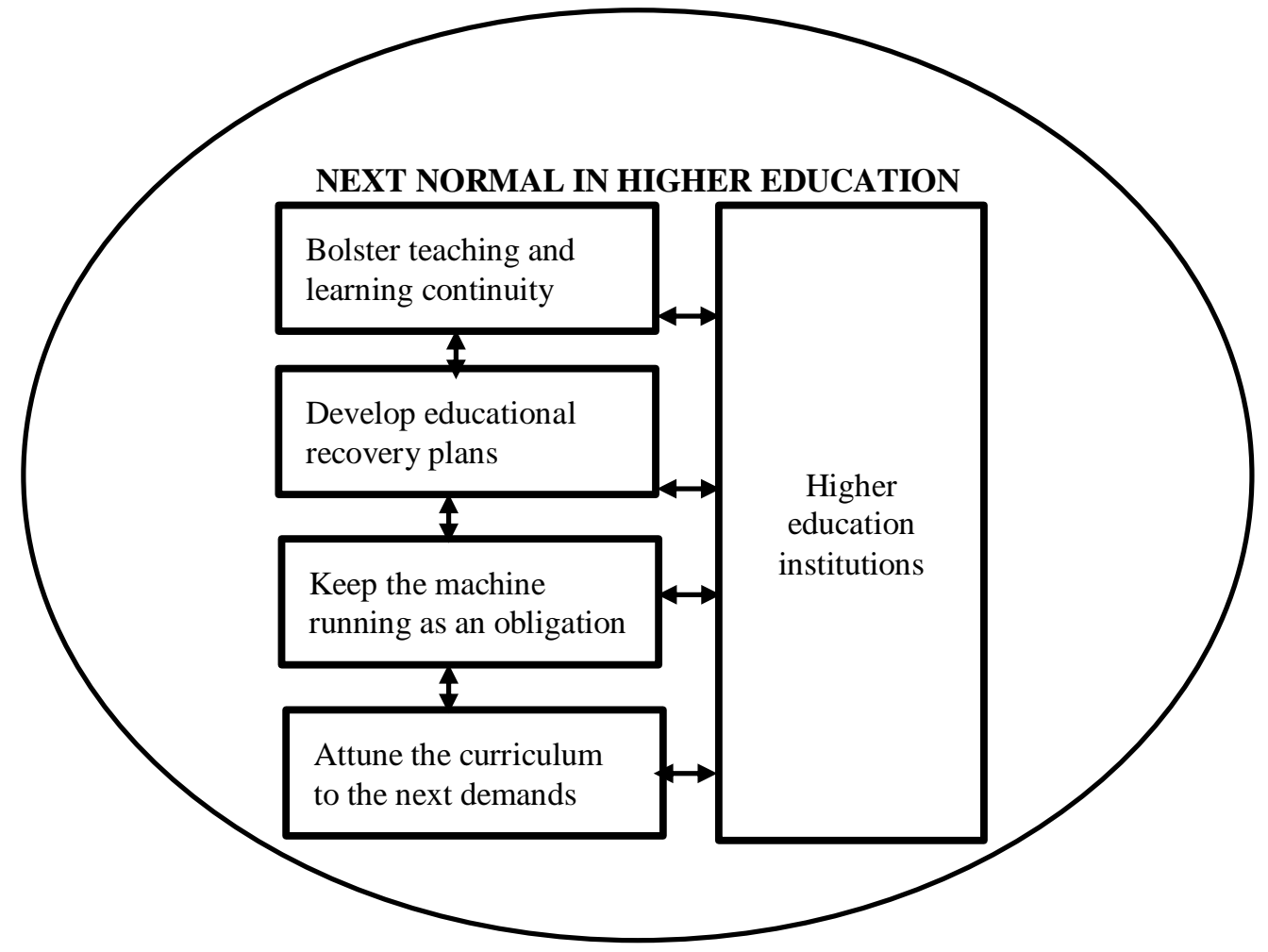

Figure 1. Next Normal Framework in Higher Education

[Figure 1] depicts the "Next Normal Framework in Higher Education." It shows that the next normal by itself is the "how" as higher education institutions actively navigate the postCOVID-19 era. The four smaller boxes show the enabling actions in constant interaction with each other and the bigger box which represents the higher education institutions. It should be noted that the process is not linear nor cyclical. Considering the different contexts of higher education institutions, it is characterized by dynamism to allow them to take which action that suits which of their situation at any rate amid the uncertainties of the next normal.

Overall, this paper guides as regards how higher education institutions can navigate the next normal post-COVID-19 era. It is recommended that higher education authorities and teachers consider the points raised in the proposed framework in planning for the next normal. As an essay article, however, these points drawn in this paper are not definitive. They were drawn only from the experiences, observations, and reflections of the researcher which may be partial. These points have not been tested as the best solutions to the continuing crisis. Thus, other researchers should also look into the continuous evaluation as regards the 
applicability of the proposed framework in the field and offer points of improvement toward the next normal in higher education.

\section{References}

[1] Z. Zhu, X. Lian, X. Su, W. Wu, G. A. Marraro, and Y. Zeng, "From SARS and MERS to COVID-19: A brief summary and comparison of severe acute respiratory infections caused by three highly pathogenic human coronaviruses," Respiratory Research, vol.21, no.1, p.224, (2020) DOI:10.1186/s12931-020-01479-w

[2] M. A. Shereen, S. Khan, A. Kazmi, N. Bashir, and R. Siddique, "COVID-19 infection: Origin, transmission, and characteristics of human coronaviruses," Journal of Advanced Research, vol.24, pp.91-98, (2020) DOI:10.1016/j.jare.2020.03.005

[3] V. McLeod, "COVID-19: A history of coronavirus," Lab Manager, (2020) Retrieved from https://www. labmanager.com/lab-health-and-safety/covid-19-a-history-of-coronavirus-22021

[4] World Health Organization, "WHO coronavirus disease (COVID-19) dashboard," Author, (2020) Retrieved from https://covid19.who.int

[5] F. Di Pietro Biagi, P. Costa, Z. Karpiński, and J. Mazza, "The likely impact of COVID-19 on education: Reflections based on the existing literature and recent international datasets," European Commission, (2020) Retrieved from https://ec.europa.eu/jrc/en/publication/likely-impact-covid-19-education-reflections-basedexisting-literature-and-recent-international

[6] L. Espino-Díaz, G. Fernandez-Caminero, C.-M Hernandez-Lloret, H. Gonzalez-Gonzalez, and J.-L. AlvarezCastillo, "Analyzing the impact of COVID-19 on education professionals. Toward a paradigm shift: ICT and neuroeducation as a binomial of action," Sustainability, vol.12, no.14, p.5646, (2020) DOI:10.3390/su12145646

[7] A. Bozkurt, and R. C. Sharma, "Education in normal, new normal, and next normal: Observations from the past, insights from the present and projections for the future," Asian Journal of Distance Education, vol.15, no.2, pp.i-x, (2020). DOI:10.5281/zenodo.4362664

[8] K. Sneader, and S. Singhal, "Beyond coronavirus: The path to the next normal," McKinsey \& Company, (2020) Retrieved from https://www.mckinsey.com/industries/healthcare-systems-and-services/ourinsights/beyond-coronavirus-the-path-to-the-next-normal

[9] M. Mogelonsky, "The next normal is now," Mintel Blog, (2020) Retrieved from https://www.mintel.com/blog/consumer-market-news/the-next-normal-is-now

[10] M. B. Cahapay, "A reconceptualization of learning space as schools reopen amid and after COVID-19 pandemic," Asian Journal of Distance Education, vol.15, no.1, pp.269-276, (2020) DOI:10.5281/zenodo.3892969

[11] J. J. B. Joaquin, H. T. Biana, and M. A. Dacela, "The Philippine higher education sector in the time of COVID-19," Frontiers in Education, pp.5, (2020) DOI:10.3389/feduc.2020.576371

[12] A. A. Lapada, F. F. Miguel, D. A. R. Robledo, and Z. F. Alam, "Teachers' Covid-19 awareness, distance learning education experiences and perceptions towards institutional readiness and challenges," International Journal of Learning, Teaching and Educational Research, vol.19, no.6, pp.127-144, (2020) DOI:10.26803/ijlter.19.6.8

[13] R. E. Baticulon, N. R. Alberto, M. B. Baron, R. E. Mabulay, L. G. Rizada, J. J. Sy, C. J. Tiu, C. A. Clarion, and J. C. Reyes, "Barriers to online learning in the time of COVID-19: A national survey of medical students in the Philippines," medRxiv, (2020) DOI:10.1101/2020.07.16.20155747

[14] De Guzman, M. J., Pastor, C. K. L., Estira, K. L. A., Ventayen, R. J. M., \& David, C. E. V. (2020), "Source of stress and cope up mechanism of college students during the lockdown and extreme community quarantine due to COVID-19 pandemic," Journal of Critical Reviews, vol.7 no.12, pp.824-285, http://dx.doi.org/10.31838/jcr.07.12.145 
[15] M. L. Tee, C. A. Tee, J. P. Anlacan, K. J. G. Aligam, P. W. C. Reyes, V. Kuruchittham, and R. C. Hog, "Psychological impact of COVID-19 pandemic in the Philippines," Journal of Affective Disorders, vol.277, pp.379-391, (2020) DOI:10.1016/j.jad.2020.08.043

[16] J. Mateo, “As classes open, 'learning crises highlighted with millions of students left behind," One News, (2020), Retrieved from https://www.onenews.ph/as-classes-open-learning-crisis- highlighted-with-millionsof-students-left-behind

[17] E. E. Rotas, and M. B. Cahapay, "Difficulties in remote learning: Voices of Philippine university students in the wake of COVID-19 crisis," Asian Journal of Distance Education, vol.15, no.2, pp.147-158, (2020) DOI:10.5281/zenodo.4299835

[18] A. P. Santos, "In the Philippines, distance learning reveals the digital divide," The Heinrich-Böll-Stiftung European Union, (2020), Retrieved from https://eu.boell.org/en/2020/10/06/philippines-distance-learningreveals-digital-divide

[19] Commission on Higher Education, "Guidelines on the implementation of flexible learning," Author, (2020), Retrieved from https://ched.gov.ph/wp-content/uploads/DRAFT-Guidelines-Flexible-Learning_for-PublicConsultation.pdf

[20] Deloitte, "Understanding the impact of Covid-19 on higher education institutions," Author, (2020), Retrieved from https://www2.deloitte.com/ie/en/pages/covid-19/articles/covid-19-on-higher-education.html

[21] C. K. Español, "How to define the next normal after the coronavirus pandemic: An analysis of the routes to the new normal post-COVID-19 crisis," CK Español, (2020), Retrieved from https://medium.com/@CKEspanol/how-to-define-the-new-normal-post-the-covid-19-crisis-fba73f6ff896

[22] UNICEF, "Building resilient education systems beyond the COVID-19 pandemic: Considerations for education decision-makers at national, local and school levels," Author, (2020), Retrieved from https://www.unicef.org/ukraine/media/8011/file/ECAR\%20CONSIDERATIONS\%20FOR\%20EDUCATION \%20PROVISION-\%20v2.5\%20ENG.pdf

[23] Texas School Safety Center, "Resources for school recovery after COVID-19 closures," Author, (2020), Retrieved from https://txssc.txstate.edu/topics/emergency-management/articles/school-recovery-covid-19

[24] Readiness and Emergency Management for Schools, "Guide for developing high-quality school emergency operations plans," Author, (2013), Retrieved from https://rems.ed.gov/K12RecoveryAnnex.aspx.

[25] C. Deiparine, "Gov't told: Ensure students won't drop out in 2021 as face-to-face classes remain uncertain," The Philippine Star, (2020), Retrieved from https://www.philstar.com/headlines/2020/12/28/2066752/govttold-ensure-students-wont-drop-out-2021-face-face-classes-remain-uncertain

[26] C. Allen, "What are the skills required in our 'new normal' world?" Atos, (2020), Retrieved from https://atos.net/en/blog/what-are-the-skills-required-in-our-new-normal-world

[27] S. Lukins, "The 'new normal': Why digital skills matter more than ever," Top MBA, (2020), Retrieved from https://www.topmba.com/jobs/career-trends/new-normal-why-digital-skills-matter-more-ever

[28] S. Smith, "The new normal: Remote work requires new skills and old values," Forbes, (2020), Retrieved from https://www.forbes.com/sites/forbescoachescouncil/2020/10/02/the-new-normal-remote-work-requires-newskills-and-old-values/?sh=26a9a9bd1355

[29] CNN Philippines. "Job seekers must upgrade digital skills to be hired in the "new normal" - job portal" Author, (2020), Retrieved from https://cnnphilippines.com/news/2020/12/3/Job-seekers-must-upgradedigital-skills-to-be-hired-in-the--new-normal----job-portal.html

[30] M. J. Koehler, and Mishra, "What is technological pedagogical content knowledge?" Contemporary Issues in Technology and Teacher Education, vol.9, no.1, pp.60-70, (2009), Retrieved from https://citejournal.org/volume-9/issue-1-09/general/what-is-technological-pedagogicalcontent-knowledge

[31] M. B. Cahapay, "Rethinking education in the new normal Post-COVID-19 Era: A curriculum studies perspective,” Aquademia, vol.4, no.2, pp.1-5, (2020) DOI:10.29333/aquademia/8315 


\section{Author}

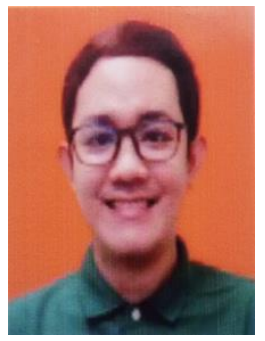

\section{Michael B. Cahapay}

Michael B. Cahapay is a licensed professional teacher and Assistant Professor at the College of Education, Mindanao State University, General Santos City, Philippines. He is currently completing his Ph.D. in Education major in Curriculum Studies at the University of the Philippines, Diliman. 